\title{
Perfil de manejo na identificação de modificações químicas do solo decorrentes do uso agrícola ${ }^{1}$
}

\section{Crop profile method in the identification of transformations in soil attributes by agricultural use}

\author{
Gustavo Adolfo de Freitas Fregonezi ${ }^{2 *}$; Carlos Roberto Espindola ${ }^{3}$
}

\begin{abstract}
Resumo
O estudo foi realizado no ano de 2002, na região Norte do Estado do Paraná, município de Rolândia, na Fazenda Jaú e teve como objetivo avaliar as modificações químicas de um Latossolo Vermelho distroférrico, comparando-se o sistema convencional com cultivo contínuo de cana-de-açúcar utilizado pela Cooperativa Agrícola de Rolândia e o sistema plantio direto com a cultura de trigo em rotação com outras culturas anuais, ambos com 8 anos de cultivos sucessivos, utilizando-se como referência uma área de vegetação nativa localizada ao lado dos sistemas avaliados. Foram abertas seis trincheiras em cada sistema avaliado, para realização do estudo morfológico pelo método do perfil de manejo utilizado na identificação das unidades morfologicamente homogêneas que serviram para nortear a retirada de amostras para as análises químicas. O Sistema plantio direto melhorou as condições químicas do solo nos primeiro $40 \mathrm{~cm}$ de profundidade. O sistema convencional com cultivo de cana-de-açúcar esgota o solo em determinadas regiões em relação a outras. O método do perfil de manejo permitiu uma adequada percepção das principais alterações encontradas nos tratamentos estudados e se mostrou muito útil na delimitação de regiões distintas, facilitando a amostragem.

Palavras-chave: Perfil de manejo, morfologia e estrutura dos solos, cana-de-açúcar, trigo, propriedades físicas e químicas, plantio direto
\end{abstract}

\begin{abstract}
The study was carried in 2002, in Rolandia, north of Paraná State, and had as objective to asses the chemistry modifications on a clayey Oxisol, comparing the conventional management system of sugar cane used by growers of Rolandia Cooperative Agriculture, and the systems of no tillage with wheat crop in rotation with others crops, both with eight years of succession, using as reference a native vegetation area localized beside the evaluated systems. Six trenches were digged in each system, for carrying about morphological study by the method of Crop Profile. Based on the identification of the homogeneous morphological units found in the description of the soil profile, samples were taken for chemistry analysis. No tillage system improved the main chemistry and morphological soil characteristics in the 0-0.40 m layer. Sugar cane conventional system exhausts the soil in some profile structures. The Crop Profile Method helped to have an appropriate notion about the main changes found in the studied treatments.
\end{abstract}

Key words: Management profile, structure, soil morphology, physical and chemical properties, sugar cane and wheat

1 Parte da Tese de Doutorado do primeiro autor, apresentada à Universidade Estadual de Campinas - Unicamp.

2 Faculdade de Engenharia Agrícola - FEAGRI, Universidade Estadual de Campinas - Unicamp. Caixa postal 6011, CEP 13083-

875, Barão Geraldo, Campinas (SP). Bolsista da CAPES.; E: mail: gustavofregonezi@yahoo.com.br

3 Professor Colaborador da Faculdade de Engenharia Agrícola - FEAGRI, Universidade Estadual de Campinas - Unicamp.

* Autor para correspondência 


\section{Introdução}

Conhecer bem o solo a partir de observações morfológicas detalhadas facilita compreender seu funcionamento, entretanto, na prática, a grande parte dos estudos de solo é realizada em amostras obtidas sem um prévio estudo morfológico, que permita melhor situar o problema. Freitas e Blancaneaux (1990), Ralish et al. (1991) e Neves et al. (2003) demonstraram a necessidade de reconhecer minuciosamente a estrutura do solo no campo, antes da realização da amostragem. Isso vem sendo praticado com a utilização da metodologia referida por "perfil cultural", que identifica unidades morfologicamente homogêneas (UMHs), permitindo a amostragem de setores do perfil do solo que revelam diferenciações, determinado uma visão diferenciada dos problemas agronômicos, particularmente na análise dos efeitos da exploração agrícola do solo; daí a pertinência da designação "perfil de cultivo" (SOARES; ESPINDOLA, 2001), ou mais recentemente "perfil de manejo" (PICCININ, 2005). O perfil de manejo tem se revelado também como o meio mais adequado para sondagem dos locais de coleta de amostras para análises físicas, químicas e biológicas (MEDINA, 1993; FREGONEZI et al., 2000, 2001).

O cultivo contínuo de uma só espécie costuma provocar o esgotamento do solo em determinados elementos e quando o ecossistema natural é substituído por uma cultura submetida a um manejo intensivo, como a cana-de-açúcar, o estoque de $\mathrm{C}$ do solo decresce substancialmente em relação ao sistema natural, não sendo recuperado (CERRI, 1986).

A vantagem da rotação de culturas em relação à monocultura está na alternância de espécies que possuem exigências nutricionais distintas, quantidade de material vegetal que retorna ao solo e a reciclagem de nutrientes diferenciados, além de explorarem diferentes regiões e profundidades do solo. Segundo constatações de Raij (1981), a matéria orgânica, apesar de ocorrer em teores baixos, contribuiu com aproximadamente $56 \%$ da CTC total, no caso específico do Latossolo Vermelho argiloso derivado de rochas básicas. Esses dados ressaltam a importância de um manejo adequado da matéria orgânica para estes solos.

Os teores de fósforo nos solos tropicais são muito reduzidos, e seu acúmulo no solo, principalmente, nas camadas superficiais do sistema plantio direto, explica-se pela baixa mobilidade e solubilidade de seus compostos, principalmente em solos de natureza ácida que contenham altos teores de argila, sesquióxidos de ferro e alumínio (RAIJ, 1981). Mas, segundo Sá (1993) e Muzilli (1981, 1985), o acúmulo superficial de fósforo estaria estreitamente relacionado com a presença de material orgânico na superfície.

Trabalhos realizados por Muzilli (1985) e Sidiras e Pavan (1985) indicaram que o potássio é encontrado no solo sob a forma de compostos de alta solubilidade, e que a maior infiltração de água no sistema de plantio direto possibilitou redistribuição do nutriente ao longo do perfil. Segundo Centurion, Demattê e Fernandes (1985), Muzilli (1985) e Sá (1993), elementos móveis, como por exemplo, o potássio, podem ou não acumular-se em superfície, dependendo do tipo de solo, do regime hídrico, dos teores de matéria orgânica e da quantidade adicionada na adubação.

Centurion, Demattê e Fernandes (1985) e Muzilli (1985) relataram que o cálcio e magnésio têm tendência ao acúmulo na superfície e diminuição gradativa com a profundidade. Isso ocorre em virtude da aplicação de calcário em superfície e, segundo Santos e Roman (1989), o efeito residual da calagem em semeadura direta é de 2,5 anos após a aplicação, enquanto que em solos cultivados convencionalmente esse efeito é de 5 anos.

O presente trabalho teve como objetivo utilizar a descrição morfológica do solo para avaliar a influência do sistema convencional com cultivo contínuo de cana-de-açúcar e do sistema de semeadura direta com rotação de culturas sobre as 
características químicas de um Latossolo argiloso do Norte do Paraná, procurando quantificar e qualificar as modificações decorrentes do manejo.

\section{Material e Métodos}

O experimento foi realizado em área da Cooperativa Agrícola de Rolândia (COROL), localizada na Fazenda Jaú ( $\cong 23^{\circ} 30^{\prime} \mathrm{S}, 51^{\circ} 20^{\prime} \mathrm{W}$ ), município de Rolândia, no ano agrícola de 2002. O solo fora classificado Latossolo Vermelho distroférrico, de acordo com o Sistema Brasileiro de Classificação de Solos (EMPRESA BRASILEIRA DE PESQUISA AGROPECUÁRIA - EMBRAPA, 1999). O clima é Cfa (clima temperado quente com precipitação em todos os meses do ano e verão quente com temperaturas maiores que 22 $\left.{ }^{\circ} \mathrm{C}\right)$ segundo classificação de Köeppen; o relevo é plano a suave ondulado, com excelente potencial agrícola, para culturas tanto de ciclo curto quanto de ciclo longo, como têm demonstrado as explorações agrícolas nessa região (EMBRAPA; FUNDAÇÃO INSTITUTO AGRONÔMICO DO PARANÁ IAPAR, 1984).

Foram avaliados 3 áreas:

a) uma área com a cultura de cana-de-açúcar, com 8 anos de produção contínua em sistema convencional de manejo (com 2 ha).

b) uma área com trigo em rotação com outras culturas anuais no sistema plantio direto, com 8 anos (com 2 ha).

c) uma área de vegetação nativa, localizada ao lado das anteriores, caracterizada pela ausência de madeiras nobres, como por exemplo, peroba (Aspidosperma cylindrocarpon ) e araucária (Araucária angustifólia) e presença de espécies pioneiras, como a imbaúba (Cecropia pachystachya) crescendo nas clareiras e bordas indicando a ação do homem. Constituída por espécies perenifólia a subperenifólia. Os parâmetros pedológicos desta área foram usados como referência.
Tanto a área com cana-de-açúcar no sistema convencional de manejo como a área com trigo no sistema plantio direto foram cultivadas com café até o ano agrícola de 1985.

A área com a cultura de cana-de-açúcar está em conformidade com as práticas manejo adotadas pelos produtores da região, conforme descrição a seguir. O espaçamento entre as linhas de plantio é de $1,30 \mathrm{~cm}$. Antes do plantio da cana-de-açúcar, é usualmente realizada uma amostragem do solo, de 0 a $30 \mathrm{~cm}$, utilizando-se o índice de saturação por bases $(\mathrm{V} \%)$ entre 70 e $80 \%$ para proceder a correção do $\mathrm{pH}$. No plantio, os toletes com 4 a 5 gemas cada um são distribuídos mecanicamente, sendo estabelecidas 15 gemas por metro linear. A colheita foi realizada manualmente, após a queima e a cana-de-açúcar enleirada foi recolhida com tratores até os caminhões que transportam a cana para a usina. No início da brotação a palha foi enleirada, o controle de plantas daninhas e o cultivo das soqueiras, foi feito com implemento específico que realiza três operações (escarificação, adubação e gradagem) denominado de tríplice operação. No fim do perfilhamento, realizou-se a adubação de cobertura. Tanto para a adubação em cobertura quanto para a realizada no momento do cultivo das soqueiras, considerou-se a exigência das variedades dos talhões.

Antes da implantação do sistema plantio direto, as áreas foram corrigidas, visando-se saturação por bases entre 70 e $80 \%$ (V\%). Foi adotado um sistema de rotação de culturas utilizando as seguintes culturas: trigo, aveia, milho - inverno; soja, milho - verão. Nesse sistema a aveia era utilizada como adubação verde em uma parte da área. Antes do plantio foi utilizado herbicidas para o controle das plantas daninhas. No momento da avaliação a área estava sendo cultivada com trigo com espaçamento entre linhas de $15 \mathrm{~cm}$.

As descrições morfológicas e a retirada de amostras foram efetuadas no final da estação chuvosa do ano agrícola de 2002 em 6 trincheiras abertas 
em cada área (6 em cada área avaliada, totalizando 18 trincheiras). As descrições morfológicas dos perfis de solos foram feitas utilizando-se o método do perfil de manejo (PICCININ, 2005) com a delimitação de cada volume, denominado unidade morfologicamente homogênea (UMH). A delimitação das UMHs foi realizada tanto em profundidade como lateralmente, a partir de critérios como: forma, tamanho e distribuição dos elementos estruturais; presença de poros visíveis a olho nu e a continuidade destes; forma e dureza dos agregados e torrões, além de outros fatores, com base em designações utilizadas por Tavares Filho et al., (1999). As trincheiras possuíam $130 \mathrm{~cm}$ de comprimento x $100 \mathrm{~cm}$ de largura x $100 \mathrm{~cm}$ de profundidade e foram abertas perpendicularmente em relação as linhas de cana-de-açúcar e de trigo. As trincheiras na área de cana-de-açúcar abrangeram duas linhas por trincheira, enquanto que na cultura de trigo foram nove linhas.

Para cada unidade morfologicamente homogênea (UMH) encontrada na descrição do perfil foram retiradas amostras indeformadas para a realização de análises químicas: $\mathrm{pH}$, carbono orgânico e complexo sortivo, de acordo com Embrapa (1997).

\section{Resultados e Discussões}

Na Figura 1 observa-se o perfil médio de canade-açúcar no sistema convencional, na Figura 2 o perfil médio de trigo no sistema plantio direto e na Figura 3 o perfil de referência (mata).

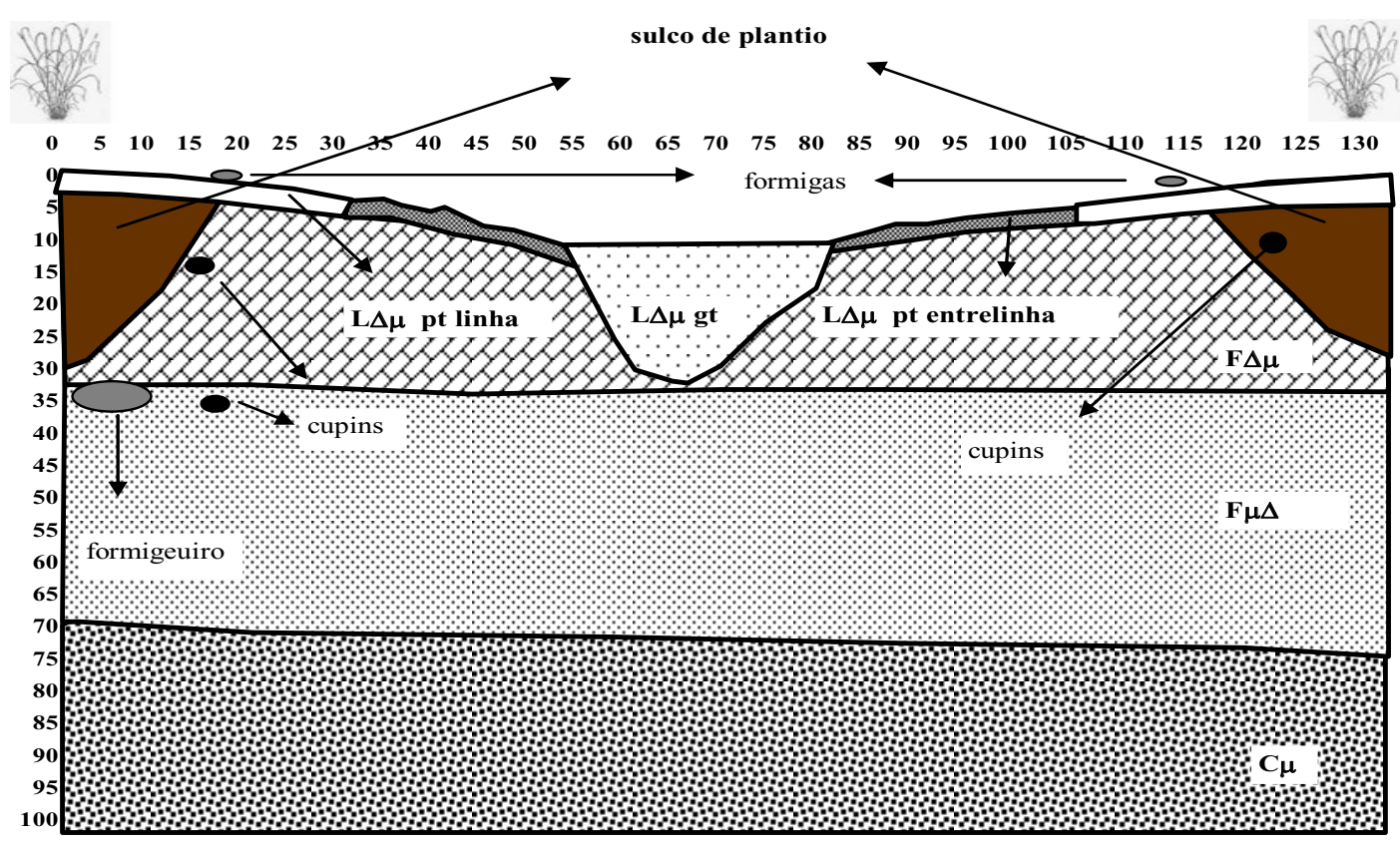

Figura 1. Perfil médio de cana-de-açúcar no sistema convencional de manejo. 


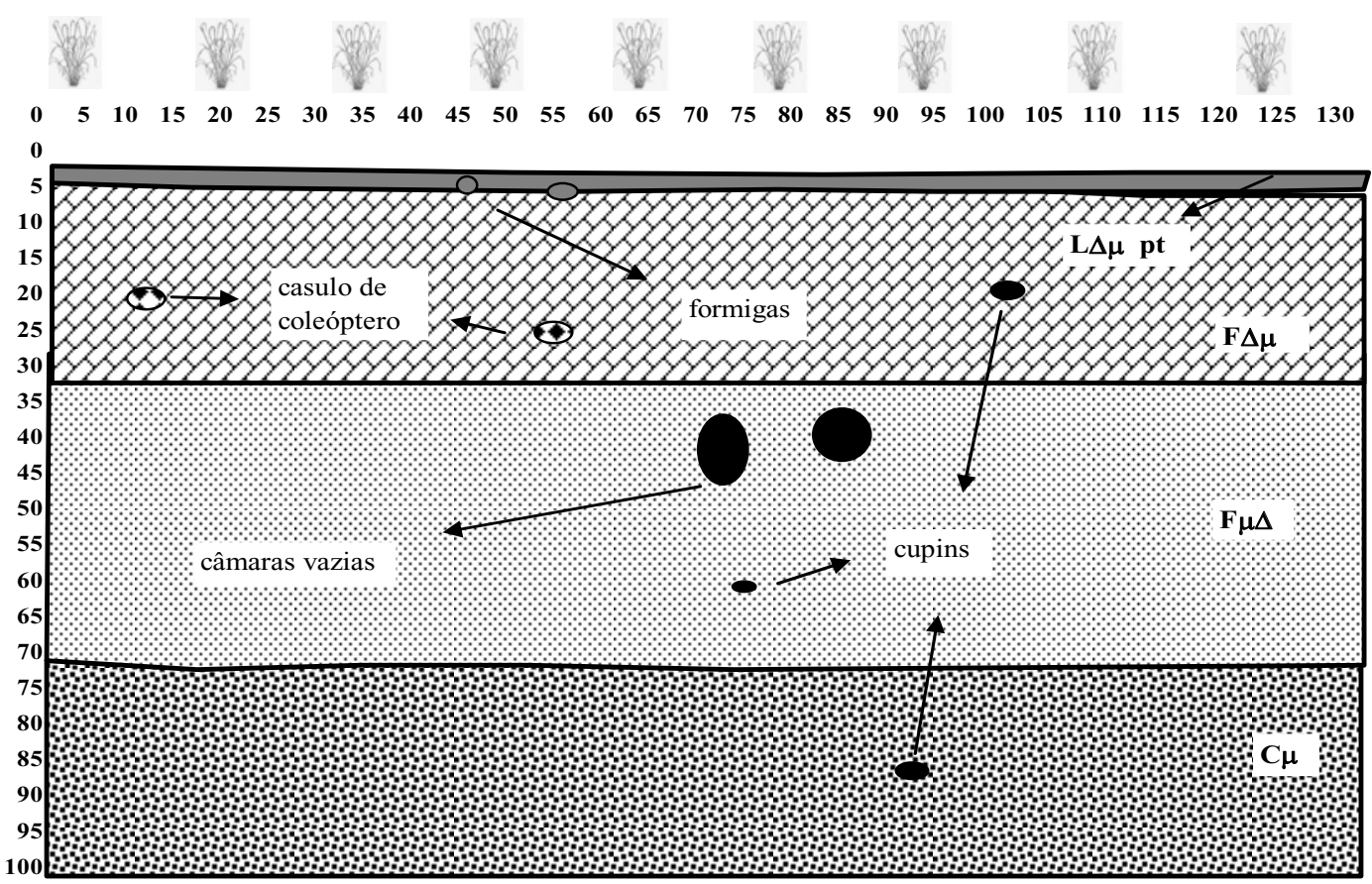

Figura 2. Perfil médio de trigo no sistema plantio direto.

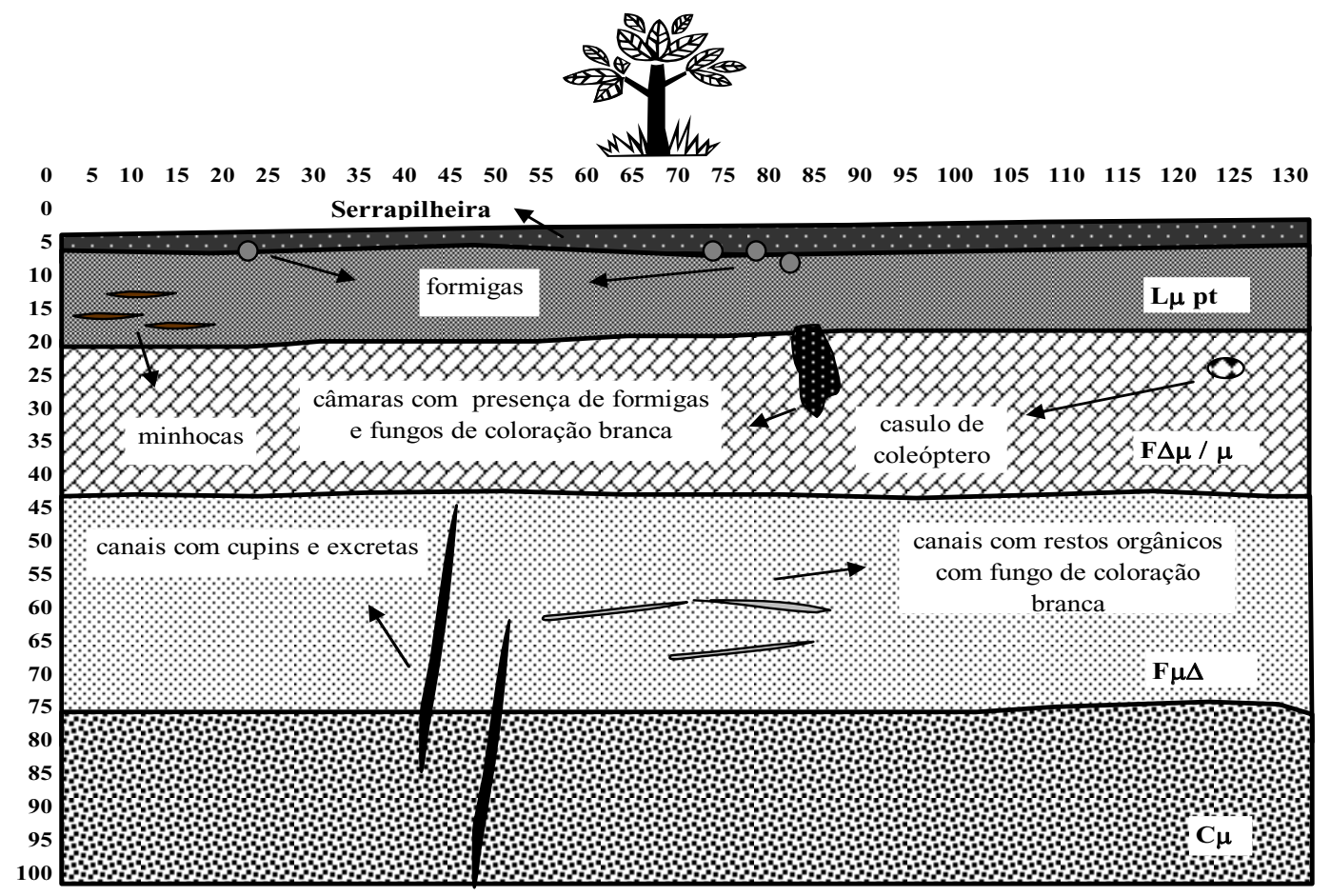

Figura 3. Perfil médio de referência (mata nativa). 
A descrição morfológica permitiu a identificação de diferentes regiões dentro dos perfis que foram identificadas com siglas de acordo com a metodologia do perfil cultural segundo Tavares Filho et al. (1999). O termo "pt" encontrado depois de cada sigla nas UMHs, como por exemplo L $\Delta \mu \mathrm{pt}$, indicam a presença de pequenos torrões e "gt" na UMH L $\Delta \mu$ gt indicam a presença de grandes torrões como foi estabelecido por Fregonezi et al. (2001). As observações demonstram perfis mais homogêneos nas áreas de mata e de trigo em plantio direto em comparação com a área de cana-de-açúcar, principalmente nos primeiros $30 \mathrm{~cm}$ de profundidade.
Com a análise dos resultados da Figura 4 podese afirmar que os teores de cálcio têm tendência ao decréscimo em profundidade, o que está de acordo com resultados obtidos por Centurion, Demattê e Fernandes (1985), Muzilli (1985), Sá (1993) e Canellas et al. (2003). Teores mais elevados de cálcio são observados na área com cana abaixo de $70 \mathrm{~cm}$ de profundidade, em parte decorrente da decomposição das raízes. $\mathrm{Na}$ área com cana-de-açúcar no sistema convencional e com trigo no sistema plantio direto os teores até $30 \mathrm{~cm}$ são mantidos graças ao efeito residual da aplicação de calcário, o que concorda com o que refere Santos e Roman (1989).

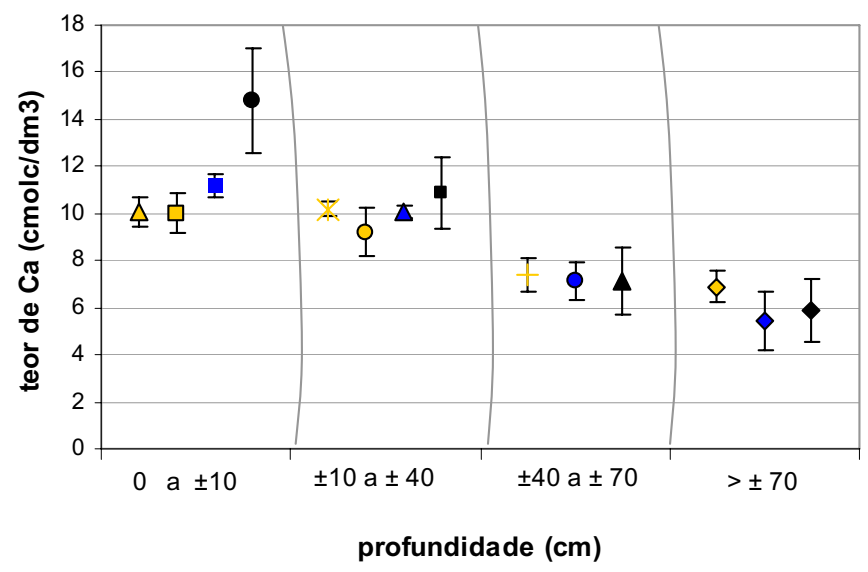
$\Delta \mathrm{L} \Delta \mu \mathrm{pt}$ entrelinha /cana
$\square \mathrm{L} \Delta \mu \mathrm{pt}$ linha / cana
- $\mathrm{L} \Delta \mu \mathrm{pt} /$ plantio direto
- $\mathrm{L} \mu \mathrm{pt} / \mathrm{mata}$
K $\mathrm{L} \Delta \mu \mathrm{gt} / \mathrm{cana}$
- $\mathrm{F} \Delta \mu /$ cana
$\Delta \mathrm{F} \Delta \mu /$ plantio direto
- $\mathrm{F} \Delta \mu / \mu /$ mata
+ F $\mu \Delta /$ cana
- $F \mu \Delta /$ plantio direto
$\Delta \mathrm{F} \mu \Delta / \mathrm{mata}$
$\diamond \mathrm{C} \mu /$ cana
- $\mathrm{C} \mu /$ plantio direto
- $\mathrm{C} \mu /$ mata

Figura 4. Teores de cálcio e desvios padrões das UMH nos tratamentos com cana-de-açúcar no sistema convencional, com trigo no sistema plantio direto e na mata nativa em diferentes profundidades.

Como a cultura de cana é mais tolerante a acidez, conforme relataram Raij e Quaggio (1997), os teores de cálcio são reduzidos visto que os intervalos entre calagens são sempre maiores.

Os resultados em superfície indicam que a mata nativa apresenta os maiores teores de $\mathrm{Ca}$, principalmente nos primeiros $10 \mathrm{~cm}$, que podem ser explicados pela mineralização da matéria orgânica depositada em superfície, o que já fora devidamente comprovado por diversos autores (SIDIRAS; PAVAN, 1985; SANTOS; SIQUEIRA, 1996; SÁ,
1993; CORREA; CONSOLINI; CENTURION, 2001), e pelo acúmulo nas primeiras camadas do solo, já que se trata de um elemento pouco móvel, conforme Centurion, Demattê e Fernandes (1985) e Muzilli (1985). Pode-se observar também, nos primeiros $10 \mathrm{~cm}$ de profundidade, valores mais elevados de cálcio no sistema plantio direto em relação ao cultivo de cana devido à rotação de culturas que não provoca o esgotamento de nutrientes pela exigência diferenciada das culturas, como já relataram anteriormente Maria e Castro (1993) e Mengel e Kirby (1987). 


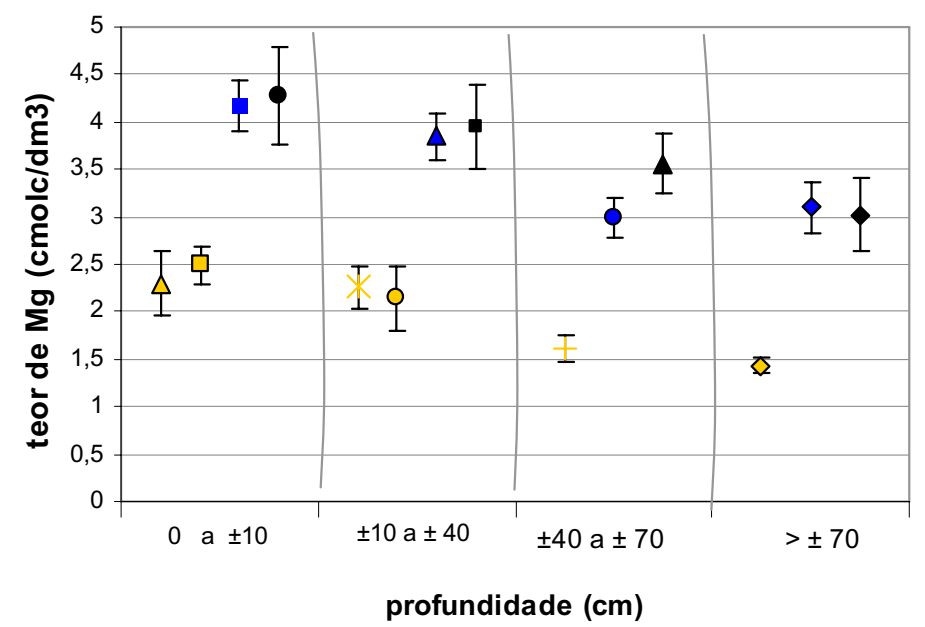

$\Delta \mathrm{L} \Delta \mu \mathrm{pt}$ entrelinha /cana

$\square \mathrm{L} \Delta \mu \mathrm{pt}$ linha / cana

- $\mathrm{L} \Delta \mu \mathrm{pt} /$ plantio direto

- Lu pt / mata

* L $\Delta \mu$ gt /cana

- $\mathrm{F} \Delta \mu /$ cana

$\Delta \mathrm{F} \Delta \mu /$ plantio direto

- F $\Delta \mu / \mu /$ mata

$+\mathrm{F} \mu \Delta / \mathrm{cana}$

- $\mathrm{F} \mu \Delta /$ plantio direto

$\Delta \mathrm{F} \mu \Delta /$ mata

$\diamond \mathrm{C} \mu /$ cana

- $\mathrm{C} \mu /$ plantio direto

- $\mathrm{C} \mu$ / mata

Figura 5. Teores de magnésio e desvios padrões das UMH nos tratamentos com cana-de-açúcar no sistema convencional, com trigo no sistema plantio direto e na mata nativa em diferentes profundidades.

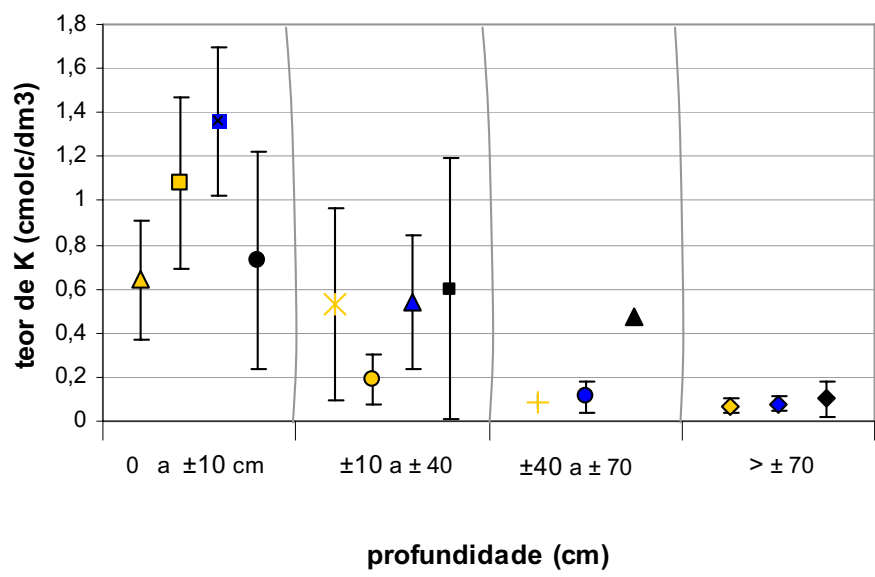

$\Delta \mathrm{L} \Delta \mu \mathrm{pt}$ entrelinha /cana

$\square \mathrm{L} \Delta \mu \mathrm{pt}$ linha / cana

$\mathbf{\mathrm { L }} \Delta \mu \mathrm{pt} /$ plantio direto

- $\mathrm{L} \mu \mathrm{pt} / \mathrm{mata}$

* L $\Delta \mu$ gt /cana

- F $\Delta \mu /$ cana

$\Delta \mathrm{F} \Delta \mu /$ plantio direto

- $\mathrm{F} \Delta \mu / \mu /$ mata

+ F $\mu \Delta /$ cana

- $\mathrm{F} \mu \Delta /$ plantio direto

$\Delta \mathrm{F} \mu \Delta /$ mata

$\diamond \mathrm{C} \mu /$ cana

$\diamond \mathrm{C \mu} /$ plantio direto

- $\mathrm{C} \mu /$ mata

Figura 6. Teores de potássio e desvios padrões das UMH nos tratamentos com cana-de-açúcar no sistema convencional, com trigo no sistema plantio direto e na mata nativa em diferentes profundidades. 


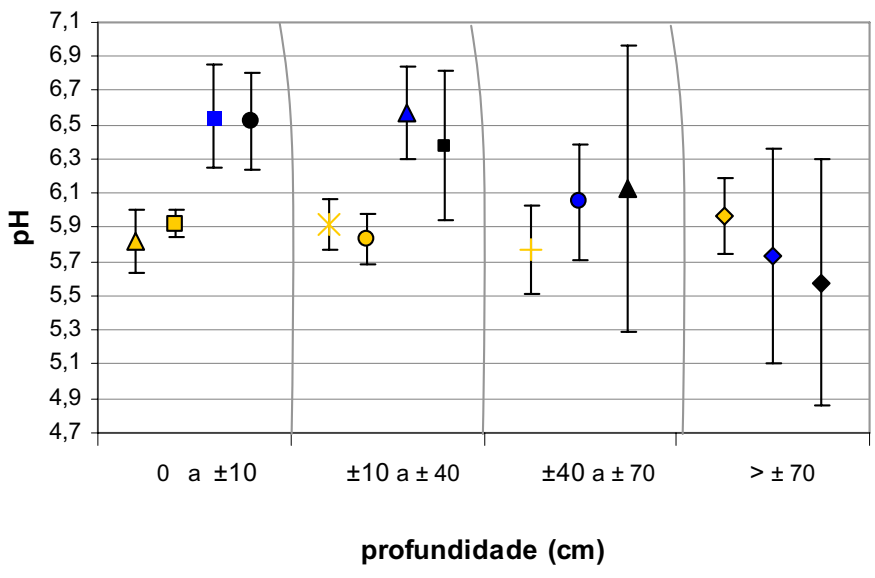
$\Delta \mathrm{L} \Delta \mu \mathrm{pt}$ entrelinha /cana
$\square \mathrm{L} \Delta \mu \mathrm{pt}$ linha / cana
- $\mathrm{L} \Delta \mu \mathrm{pt} /$ plantio direto
- L $\mu \mathrm{pt} /$ mata
$* \mathrm{~L} \Delta \mu \mathrm{gt} / \mathrm{cana}$
O F $\Delta \mu /$ cana
$\Delta \mathrm{F} \Delta \mu /$ plantio direto
- $\mathrm{F} \Delta \mu / \mu /$ mata
$+\mathrm{F} \mu \Delta /$ cana
- $\mathrm{F} \mu \Delta /$ plantio direto
$\Delta \mathrm{F} \mu \Delta /$ mata
$\diamond \mathrm{C} \mu /$ cana
$\diamond \mathrm{C} \mu /$ plantio direto
- $\mathrm{C} \mu /$ mata

Figura 7. Valores de pH e desvios padrōes das UMH nos tratamentos com cana-de-açúcar no sistema convencional, com trigo no sistema plantio direto e na mata nativa em diferentes profundidades.

O cultivo com cana-de-açúcar reduziu os teores de magnésio (Figura 5) em relação a mata nativa e ao plantio direto, em todas as profundidades analisadas, o que demonstra a contínua exigência do nutriente pela cultura de cana-de-açúcar e o intervalo entre as calagens maiores, que não é observado no sistema plantio direto, em virtude de calagens mais freqüentes e das exigências diferenciadas por parte das culturas que fazem parte da rotação. Fato parecido é observado na mata nativa cujos teores são mantidos mais elevados pela decomposição de folhas e raízes (SIDIRAS; PAVAN, 1985; SANTOS; SIQUEIRA, 1996; SÁ, 1993; CANELLAS et al., 2003).
Os resultados obtidos para o elemento potássio podem ser observados na Figura 6 e indicam que o cultivo dos solos, provocaram aumento nos seus teores, principalmente nos primeiros $10 \mathrm{~cm}$, o que já fora relatado por Muzilli (1985), Centurion, Demattê e Fernandes (1985), Sá (1993), Sidiras e Pavan (1985). $\mathrm{Na}$ área com trigo pelo sistema plantio direto observouse pouca variação dos resultados em uma mesma profundidade, enquanto que naárea com cana-de-açúcar os valores de potássio na linha são quase duas vezes maiores que os da entrelinha, o que permite verificar que a adubação de manutenção não é suficiente para elevar o potássio na entrelinha ou é realizada de forma localizada sempre na linha de cultivo.

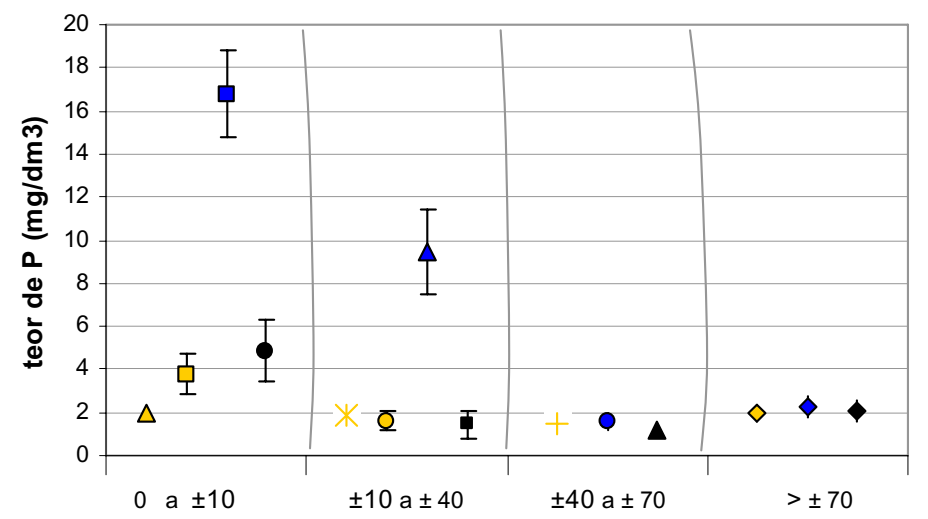

$\Delta \mathrm{L} \Delta \mu \mathrm{pt}$ entrelinha /cana

$\square \mathrm{L} \Delta \mu \mathrm{pt}$ linha / cana

- $\mathrm{L} \Delta \mu \mathrm{pt} /$ plantio direto

- $\mathrm{L} \mu \mathrm{pt} / \mathrm{mata}$

* L $\Delta \mu$ gt /cana

- $\mathrm{F} \Delta \mu /$ cana

$\Delta \mathrm{F} \Delta \mu /$ plantio direto

- F $\Delta \mu / \mu /$ mata

$+\mathrm{F} \mu \Delta /$ cana

- $F \mu \Delta /$ plantio direto

$\Delta \mathrm{F} \mu \Delta / \mathrm{mata}$

$\diamond \mathrm{C} \mu /$ cana

- $\mathrm{C} \mu /$ plantio direto

- $\mathrm{C} \mu /$ mata

Figura 8. Teores de fósforo e desvios padrões das UMH nos tratamentos com cana-de-açúcar no sistema convencional, com trigo no sistema plantio direto e na mata nativa em diferentes profundidades. 
Os resultados de $\mathrm{pH}$ das UMHs localizadas até $45 \mathrm{~cm}$ de profundidade (Figura 7), demonstram que a cultura de cana-de-açúcar sob sistema convencional de manejo apresentou sempre valores mais ácidos, quando comparados com a cultura de trigo sob sistema plantio direto e com a mata nativa, evidenciando os efeitos dos intervalos longos entre as calagens, podendo isso ser apontado como uma das limitações que determinam a reforma dos canaviais. Entretanto Raij e Quaggio (1997) verificaram que a cultura de cana-de-açúcar é muito tolerante à acidez do solo e segundo Rossetto et al. (2004) a cana só responde em termos de produtividade a calagens quando o pH do solo estiver abaixo de 4,4.

Os valores de $\mathrm{pH}$ obtidos no sistema plantio direto e na mata nativa estão mais próximos da neutralidade e mostram que os teores mais elevados de matéria orgânica amenizam o efeito da acidificação, como mencionado por Sidiras e Pavan (1985).

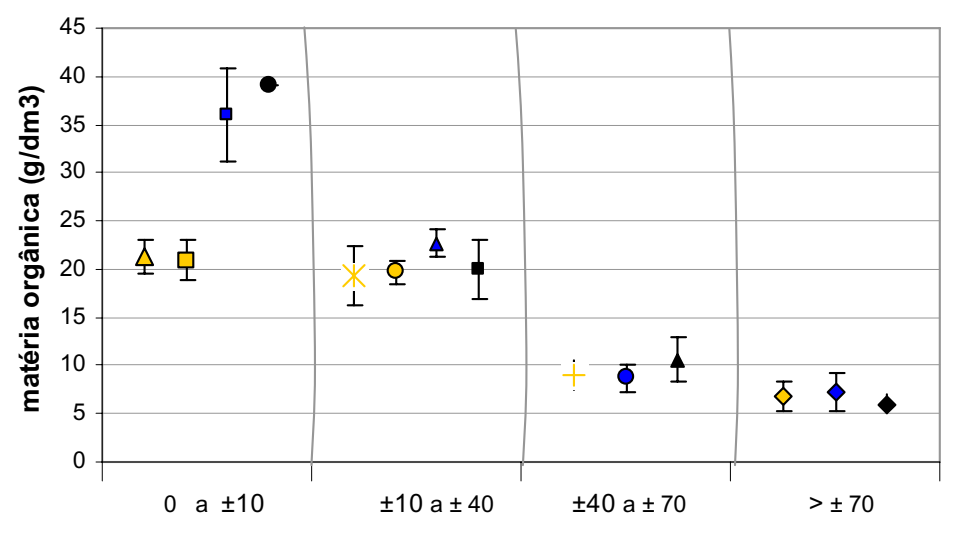

$\Delta \mathrm{L} \Delta \mu \mathrm{pt}$ entrelinha /cana

$\square \mathrm{L} \Delta \mu \mathrm{pt}$ linha / cana

- L $\Delta \mu \mathrm{pt} /$ plantio direto

- $\mathrm{L} \mu \mathrm{pt} / \mathrm{mata}$

* L $\Delta \mu$ gt /cana

- $\mathrm{F} \Delta \mu / \mathrm{cana}$

$\Delta \mathrm{F} \Delta \mu /$ plantio direto

- F $\Delta \mu / \mu /$ mata

$+\mathrm{F} \mu \Delta /$ cana

- $F \mu \Delta /$ plantio direto

- $\mathrm{F} \mu \Delta /$ mata

$\diamond \mathrm{C} \mu /$ cana

$\diamond \mathrm{C} \mu /$ plantio direto

profundidade $(\mathrm{cm})$

- $\mathrm{C} \mu /$ mata

Figura 9. Teores de matéria orgânica e desvios padrões das UMH nos tratamentos com cana-de-açúcar no sistema convencional, com trigo no sistema plantio direto e área com mata nativa em diferentes profundidades.

Na Figura 8, observou-se que a área com trigo no sistema plantio direto favorece o acúmulo de fósforo até $30 \mathrm{~cm}$, concordando com Sá (1993) e Muzilli (1985). Também devemos considerar que nos Latossolos grande parte dos fosfatos presentes não são móveis, e sim fixados, ou seja, tornam-se não assimiláveis pelos vegetais. Este comportamento já havia sido relatado anteriormente por Raij (1981). Além dos fatores já mencionados, deve-se considerar que são solos originados a partir de rochas pobres neste elemento.

O sistema convencional com cana-de-açúcar, promoveu, em relação a mata nativa, reduções de fósforo, além da variação nas quantidades, também observadas por Canellas et al. (2003). Este fato já tinha sido detectado para o elemento potássio, que é quase o dobro quando se compara as UMHs L $\Delta \mu$ pt da linha com a da entrelinha. Estas alterações podem não influenciar a produção, mas devido ao ciclo longo, e considerando que a maioria das áreas produtoras de cana-de-açúcar são arrendadas pelas usinas, os proprietários seriam prejudicados, pois o manejo adotado empobrece o solo na entrelinha da cultura.

Os resultados de matéria orgânica (Figura 9) nos perfis estudados evidenciam que a deposição de resíduos pelo sistema plantio direto foi superficial (0 a $4 \mathrm{~cm})$, mas o suficiente para devolver valores 
próximos dos obtidos para a mata nativa, o mesmo foi constatado em inúmeros trabalhos, tais como: Sidiras e Pavan (1985); Muzilli (1985); Centirion, Demattê e Fernandes (1985); Santos e Siqueira (1996); Sá (1993); Morrison, Gawander e Ram (2005); Canellas et al. (2003).

Este aumento de carbono orgânico em superfície, em regiões tropicais onde a mineralização é intensa, devolve ao solo grande parte dos nutrientes extraídos pelas culturas. Neste aspecto, o cultivo de cana-de-açúcar no sistema tradicional de manejo tem demonstrado grande fragilidade em relação ao sistema plantio direto.

O sistema convencional com cana-de-açúcar utilizando a queima antes da colheita acelera mineralização da matéria orgânica desfavorecendo a formação de substâncias húmicas principalmente nos primeiros $10 \mathrm{~cm}$, o que já fora anteriormente atestado por Resende et al. (2001), Maia e Ribeiro (2004) e Loss, Pereira e Brito (2006). Segundo Canellas et al. (2003) uma das formas de adicionar matéria orgânica em solos cultivados continuamente com cana-de-açúcar é promover a colheita mecanizada.

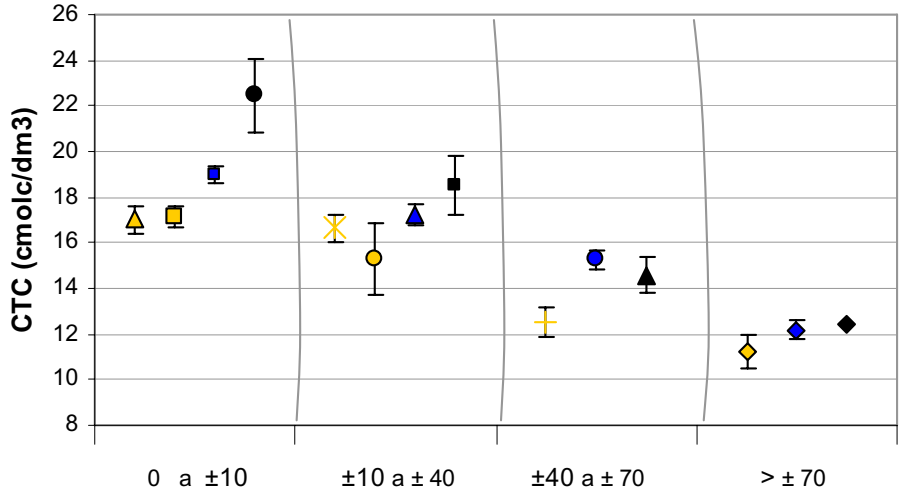

profundidade $(\mathrm{cm})$
$\Delta \mathrm{L} \Delta \mu \mathrm{pt}$ entrelinha /cana

$\square \mathrm{L} \Delta \mu \mathrm{pt}$ linha / cana

- L $\Delta \mu \mathrm{pt} /$ plantio direto

- L $\mu$ pt / mata

* L $\Delta \mu$ gt /cana

○ $\mathrm{F} \Delta \mu /$ cana

$\Delta \mathrm{F} \Delta \mu /$ plantio direto

- F $\Delta \mu / \mu /$ mata

$+F \mu \Delta /$ cana

- $\mathrm{F} \mu \Delta /$ plantio direto

$\Delta \mathrm{F} \mu \Delta / \mathrm{mata}$

$\diamond \mathrm{C} \mu /$ cana

$\diamond \mathrm{C} \mu /$ plantio direto

- $\mathrm{C} \mu$ / mata

Figura 10. Capacidade de troca de cátions (CTC) e desvios padrões das UMH nos tratamentos com cana-de-açúcar no sistema convencional, com trigo no sistema plantio direto e área com mata nativa em diferentes profundidades.

A CTC mais elevada na mata nativa (Figura 10) em relação ao sistema de plantio direto é resultado da deposição de uma diversidade maior de plantas, já que relativamente os teores são equivalentes.

$\mathrm{Na}$ área de cana-de-açúcar no sistema convencional de manejo fica nítida a influência que a queima na colheita provoca nos valores de matéria orgânica e consequentemente de CTC, atestando observações de Lopes e Guidolin (1989), Raij (1981), Correa, Consolini e Centurion (2001) e Canellas et al. (2003) a respeito da importância da matéria orgânica na constituição da CTC.

Os valores de V\%, Figura 11, são diretamente influenciados pelos teores de cálcio, magnésio, potássio. $\mathrm{Na}$ área de cana-de-açúcar no sistema convencional de manejo, os valores destes cátions são mais baixos, principalmente até $40 \mathrm{~cm}$ (profundidade do perfil do solo que foi influenciado pelo manejo), de modo que os valores de V\% foram também mais baixos. Os teores de nutrientes resultantes da mata nativa e do sistema plantio direto são elevados principalmente na superfície, devido à mineralização de parte da matéria orgânica, da adubação e da calagem determinando valores de $\mathrm{V} \%$ mais elevados. Uma forma de aumentar os valores de $\mathrm{V} \%$ no cultivo convencional de cana-deaçúcar, além de eliminar a queima durante a colheita é a utilização dos resíduos oriundos da produção de álcool e açúcar, tais como a vinhaça, torta de 
filtro, água residuária e fuligem da chaminé na cultura de cana-de-açúcar, pois muitas vezes estes resíduos são aproveitados como fontes de macro e micronutrinetes em outras culturas.

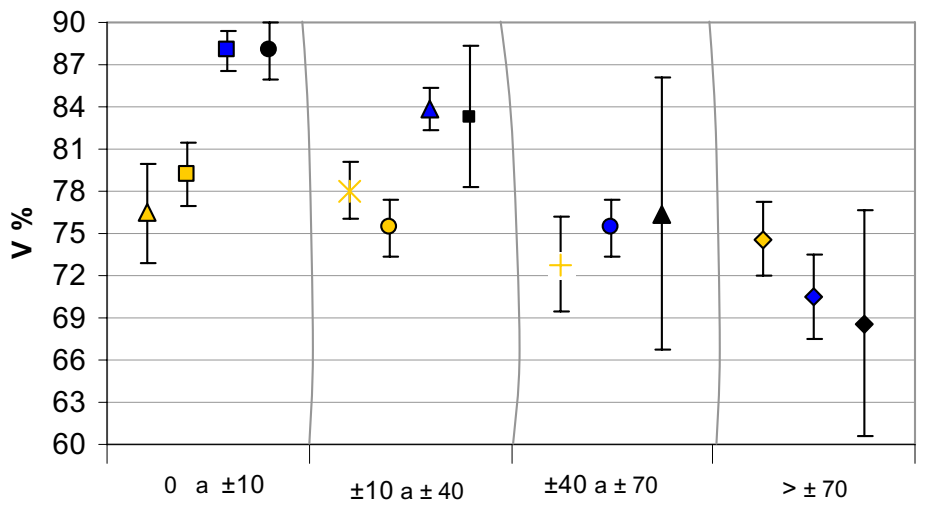

profundidade $(\mathrm{cm})$
$\Delta \mathrm{L} \Delta \mu \mathrm{pt}$ entrelinha /cana

$\square \mathrm{L} \Delta \mu \mathrm{pt}$ linha / cana

- $\mathrm{L} \Delta \mu \mathrm{pt} /$ plantio direto

- L $\mu$ pt / mata

* L $\Delta \mu$ gt /cana

O F $\Delta \mu$ / cana

$\Delta \mathrm{F} \Delta \mu /$ plantio direto

- F $\Delta \mu / \mu /$ mata

+ F $\mu \Delta /$ cana

- $\mathrm{F} \mu \Delta /$ plantio direto

$\Delta \mathrm{F} \mu \Delta /$ mata

$\diamond \mathrm{C} \mu$ / cana

- $\mathrm{C} \mu$ / plantio direto

- $\mathrm{C} \mu$ / mata

Figura 11. Saturação por bases em porcentagem e desvios padrões das UMH nos tratamentos com cana-de-açúcar no sistema convencional, com trigo no sistema plantio direto e área com mata nativa em diferentes profundidades.

\section{Conclusões}

O plantio direto melhorou os teores de fósforo e potássio do solo em relação ao da mata nativa apenas nos primeiros $10 \mathrm{~cm}$ dos perfis estudados, enquanto que o tratamento com cana-de-açúcar no sistema tradicional de manejo determinou grandes variações nos teores de nutrientes, principalmente para o fósforo e potássio nas unidades estruturais encontradas de 0 a $40 \mathrm{~cm}$, o que ocasionou o empobrecimento do solo na entrelinha da cultura de cana-de-açúcar.

Os teores de magnésio e o $\mathrm{pH}$ indicaram a necessidade da aplicação de calcário em superfície para o cultivo de cana-de-açúcar, não somente na renovação da cultura.

\section{Referências}

CANELLAS, L. P.; VELLOSO. A. C. X.; MARCIANO, C. R.; RAMALHO, J. F. G. P.; RUMJANEK, V. M. Propriedades químicas de um cambissolo cultivado com cana-de-açúcar, com preservação do palhiço e adiçãode vinhaça por longo tempo. Revista Brasileira de Ciência do Solo, Campinas, v. 27, n. 5, p. 935-944, 2003.

CENTURION, J. F.; DEMATTÊ, J. L. I.; FERNANDES, F. M. Efeitos de sistemas de preparo nas propriedades químicas de um solo sob cerrado cultivado com soja. Revista Brasileira de Ciência do Solo, Campinas, v. 3, n. 9, p. 267-270, 1985.

CERRI, C. C. Dinâmica da matéria orgânica do solo no agroecossistema cana-de-açúcar. 1986. Tese (Livre Docência) - Escola Superior de Agricultura Luiz de Queiroz, Piracicaba.

CORREA, M. C. M.; CONSOLINI, F.; CENTURION, J. F. Propriedades químicas de um latossolo vermelho distrófico sob cultivo contínuo de cana-de-açúcar (Saccharum spp.). Acta Scientiarum, Maringá, v. 23, n. 5, p. 1159-1163, 2001.

EMPRESA BRASILEIRA DE PESQUISA AGROPECUÁRIA - EMBRAPA. Centro Nacional de Pesquisa de Solos. Manual de métodos de análise de solos. 2.ed. Rio de Janeiro: EMBRAPA-CNPS, 1997. 
Sistema brasileiro de classificação de solo. Brasília: EMBRAPA-SPI, 1999.

EMPRESA BRASILEIRA DE PESQUISA AGROPECUÁRIA - EMBRAPA; FUNDAÇÃO INSTITUTO AGRONÔMICO DO PARANÁ - IAPAR. Levantamento de reconhecimento dos solos do Estado do Paraná. Curitiba: EMBRAPA/IAPAR, 1984. (Boletim técnico, 57).

FREGONEZI, G.A.F.; BROSSARD, M.; GUIMARÃES, M. F.; MEDINA, C. C. Modificações morfológicas e físicas de um latossolo argiloso sob pastagens. Revista Brasileira de Ciência do Solo, v. 25, n. 4, p. 1017-1027, 2001.

FREGONEZI, G. A. F.; GUIMARÃES, M. F.; MEDINA, C. C; BROSSARD, M. Alterações do espaço poroso de um Latossolo argiloso sob pastagens. In: INTERNATIONAL SYMPOSIUM: SOIL FUNCTIONING UNDER PASTURES IN INTERTROPICAL AREAS, 1., 2000, Brasíla. Anais... Brasília: EMBRAPA Cerrados - Soil Pasture Project, 2000.

FREITAS, P. L.; BLANCANEAUX, P. Metodologia de pesquisa em manejo do solo: estrutura e porosidade do solo. Passo Fundo: RPOCISUR/EMBRAPA/CIMMYT, 1990.

LOPES, A. S.; GUIDOLIN, J. A. Interpretação de análise de solo: conceitos e aplicações. 3.ed. São Paulo: Comitê de Pesquisa, 1989.

LOSS, A.; PEREIRA, M. G.; BRITO, R. J. Distribuição das substâncias húmicas em solos de tabuleiros sob diferentes coberturas vegetais. Revista Universidade Rural: Série Ciências da Vida, Itaguaí, v. 26, n. 1, p. $57-$ 69, 2006.

MAIA, J. L. T.; RIBEIRO, M. R. Cultivo contínuo da cana-de-açúcar e modificações químicas de um argissolo amarelo fragipânico. Pesquisa Agropecuária Brasileira, Brasília, v. 39, n. 11, p. 1127-1132, 2004.

MARIA, I. C.; CASTRO, O. M. Fósforo, potássio e matéria orgânica em um latossolo roxo, sob sistemas de manejo com milho e soja. Revista Brasileira de Ciência do Solo, Campinas, v. 17, n. 4, p. 471-477, 1993.

MEDINA, C. C. Estudo da aplicação de gesso, calcário e vinhaça na produção e enraizamento de cana-de-açúcar (Saccharum spp). 1993. Tese (Doutorado em Agronomia) - Universidade Estadual Paulista, Botucatu.

MENGEL, K.; KIRBY, E. A. Principles of plants nutrition. 4.ed. Bern: International Potash Institute, 1987.
MORRISON, R. J.; GAWANDER, J. S.; RAM, A. N. Changes in the properties of a Fijian oxisol over 25 years of sugarcane cultivation. In: INTERNATIONAL SOCIETY OF SUGARCANE TECHNOLOGIES CONGRESS, 25., 2005, Guatemala. Proceedings... Guatemala: ATAGUA/CEGICANA, 2005. p. 139-146.

MUZILLI, O. Fertilidade do solo em plantio direto. In: FANCELLI, A. L.; TORRADO, P. V. Atualização em plantio direto. Campinas: Fundação Cargill, 1985. p. 147-160.

. Manejo da fertilidade do solo. In: FUNDAÇÃO INSTITUTO AGRONÔMICO DO PARANÁ - IAPAR. Plantio direto no Paraná. Londrina: IAPAR, 1981. p. 43-57. (Circular, 23).

NEVES, C. S. V. J.; FELLER, C.; GUIMARÃES, M. F.; MEDINA, C. C.; TAVARES FILHO, J.; FORTIER, M.. Soil bulk density and porosity of homogeneous morphological units by the cropping method in clayey oxisols in Brazil. Soil \& Tillage Research, Amsterdam, v. 71, n. 2, p. 109-119, 2003.

PICCININ, J. L. Modificações no perfil de solo sob plantio direto com intervenções mecânica sob suscessão e rotação de culturas. 2005. Tese (Doutorado em Engenharia Agrícola) - Universidade Estadual de Campinas, Campinas.

RAIJ, B. Avaliação da fertilidade do solo. Piracicaba: Instituto Potassa \& Fosfato, 1981.

RAIJ, B.; QUAGGIO, J. A. Methods used for diagnosis and correction of soil acidity in Brazil: an overwiew. In: INTERNATIONAL SYMPOSIUM ON PLANTSOIL INTERACTIONS AT LOW pH, 4., 1996, Belo Horizonte. Proceedings... Campinas: Brazilian Soil Science Society, 1997. p. 205-214.

RALISCH, R.; GUIMARÃES, M. F.; MEDINA, C. C.; TAVARES FILHO, J.; DERSIGNY,C. G.;VISINTIN, L. M. B. O método do perfil cultural para auxiliar na avaliação dos efeitos do preparo sobre as estruturas do solo. In: CONGRESSO BRASILEIRO DE ENGENHARIA AGRÍCOLA, 20., 1991, Londrina. Anais... Londrina: Sociedade Brasileira de Engenharia Agrícola, 1991. p. 1374-1380.

RESENDE, A. S.; XAVIER, R. P.; SANTOS, A. O.; GONDIM, A.; BODDEY, R. M.; ALVES, B. J. R.; URQUIAGA, S. Influência da queima no estoque de carbono de um latossolo sob cultivo de cana-deaçucar. In: CONGRESSO BRASILEIRO DE CIÊNCIA DO SOLO. Fator de Produtividade Competitiva com Sustentabilidade, 28., 2001, Londrina. Anais... Londrina: Sociedade Brasileira de Ciência do Solo, 2001. p. 249. 
ROSSETTO, R.; SPIRONELLO, A.; CANTARELLA H.; QUAGGIO, J. A. Calagem para a cana-de-açúcar e sua interação com a adubação potássica. Bragantia, Campinas, v. 63, n. 1, p. 105-119, 2004.

SÁ, J. C. M. Manejo da fertilidade do solo no plantio direto. Castro: Fundação ABC, 1993.

SANTOS, H. P.; ROMAN, E. S. Rotação de culturas. XIV. Efeito de culturas de inverno e de verão na disponibilidade de nutrientes e matéria orgânica do solo, no período agrícola de 1980 a 1986. Revista Brasileira de Ciência do Solo, Campinas, v. 13, n. 3, p. 303-310, 1989.

SANTOS, H. P.; SIQUEIRA, O. J. W. Plantio direto e rotação de culturas para cevada: efeitos sobre a fertilidade do solo. Revista Brasileira de Ciência do Solo, Campinas, v. 20, n. 1, p. 163-169, 1996.
SIDIRAS, N.; PAVAN, M. A. Influencia do sistema de manejo de solo no seu nível de fertilidade. Revista Brasileira de Ciência do Solo, Campinas, v. 9, n. 3, p. 249-254, 1985.

SOARES, J. L. N.; ESPINDOLA, C. R. Atributos físicos de um argissolo sob mata nativa (Bariri, SP). In: CONGRESSO BRASILEIRO DE CIÊNCIA DO SOLO. Fator de Produtividade Competitiva com Sustentabilidade, 28., 2001, Londrina. Anais... Londrina: Sociedade Brasileira de Ciência do Solo, 2001. p. 18.

TAVARES FILHO, J.; RALISCH, R.; GUIMARÃES, M. F.; MEDINA, C. C.; BALBINO, L. C.; NEVES, C. S. V. J. Método do perfil cultural para avaliação do estado físico de solos em condições tropicais. Revista Brasileira de Ciência do Solo, Viçosa, v. 23, n. 2, p. 393399, 1999. 
